\title{
VIOLÊNCIA, CIDADANIA E DISCIPLINAMENTO: controvérsias na escola
}

\section{Violence and citizenship course: controversy in school}

\section{Jorge Luiz da Cunha ${ }^{[a]}$, Cláudia Regina Costa Pacheco ${ }^{[b]}$}

[a]D outorado em História Medieval e Modema Contemporânea, Professor titular e PróReitor de G raduação da Universidade Federal de Santa Maria (UFSM), Santa Maria, RS - Brasil, e-mail: jlcunha@ smail.ufsm.br

${ }^{[b]}$ D outoranda, Univesidade de Pelotas (UFPEL), Pelotas, RS - Brasil, e-mail crcpacheco@yahoo.com.br

\section{Resumo}

Compreender o fenômeno da violência na escola, bem como pensar soluções possíveis para o problema constitui-se o principal mote deste artigo. Partindo de uma análise histórico-cultural da educação e da constituição humana, buscou-se refletir sobre a diversidade humana e a possibilidade de construção da cidadania. Discutindo os sentidos e significados da educação para os gregos, a ideia de cidadania se sobressai a partir de um agir humano em consonância com a coletividade. Este ensaio configura-se no resultado de uma pesquisa de cunho bibliográfico, que além de discorrer sobre o sentido de "ser humano", analisou de que forma esse humano se constrói no âmbito escolar

Rev. Diálogo Educ., Curitiba, v. 9, n. 28, p. 557-569, set./ dez. 2009 
diante de práticas educativas disciplinadoras. Q uestiona-se a crise da escola e as dificuldades enfrentadas pela docência ao lidar com uma realidade cada vez mais conflituosa. A análise da obra de Bueb (2006) é um exemplo da constante procura por soluções ao depauperamento de valores morais e éticos. A incapacidade de os professores resolverem conflitos se contrapõe a uma coragem de educar necessária na atualidade. Na revisão de literatura feita, autores como Hentig (2007), Bueb (2006), Brumlik (2007), Bergmann (2006), entre outros trouxeram grandes contribuições para esta discussão. Entender os conceitos de violência, cidadania e disciplinamento é questionar nossa própria realidade, não só escolar, mas principalmente ela. Nossa tarefa enquanto educadores, seja "oleiro" ou "jardineiro", está justamente na desconstrução de uma realidade imposta, no questionamento de práticas e teorias educativas e na busca por uma convivência pacífica, que não negue conflitos, mas que saiba trabalhá-los.

Palavras-chave: Violência. D isciplina. Escola.

\begin{abstract}
Understanding the phenomenon of violence in school, and think of possible solutions to the problem is in the main motto of this article. From a historical-cultural analysis of education and human constitution, sought to reflect on the human diversity and the possibility of building citizenship. Discussing the ways and meanings of education for the Greeks, the idea of citizenship is out from a human act in line with the community. This test has become the result of a search of bibliographic stamp, which will discuss the meaning of "human being", examined the human form that is built within school before disciplinary educational practices. Questions to the school crisis and the difficulties faced by teachers in dealing with a reality increasingly confrontational. The analysis of the work of Bueb (2006) is an example of the constant search for solutions to the depletion of moral and ethical values. The inability of teachers resolve conflicts is opposed to a necessary courage to educate nowadays. In the literature review done, authors as Hentig (2007), Bueb (2006), Brumlik (2007), Bergmann (2006), among others have
\end{abstract}

Rev. Diálogo Educ., Curitiba, v. 9, n. 28, p. 557-569, set./ dez. 2009 
major contributions to this discussion. Understanding the concepts of violence, citizenship and discipline is questioning our own reality, not only school, but mainly it. Our job as educators, is "potter" or "gardener", is precisely in the deconstruction of an imposed reality, the question of educational theories and practices and the search for a peaceful coexistence, not deny conflict, but that work-learn them.

Keywords: Violence. Discipline. School.

\section{INTRODUÇÃO}

A violência é uma questão que precisa ser relacionada com a tradição pedagógica da escola moderna que adotamos no Brasil. Reduzimos, em grande medida, as práticas escolares ao esquema: professores que transmitem informações (a título de conteúdos disciplinares), verificam a capacidade de reprodução destas informações (nas avaliações de aprendizagem), formam no transcorrer dos anos de escola sujeitos aptos a cumprir ordens e executar tarefas, preparados para o mercado de trabalho (como mercadorias em liquidação).

Pensar soluções para o problema da violência passa, necessariamente, por pensar a educação, as escolas e o que fazemos nelas. Alia-se a isso, uma compreensão maior do que seja a construção humana e, sobretudo, a construção da cidadania. Aqui pretendo tratar de um aspecto desse universo, o da disciplina, ou de sua retomada, como condição de possibilidade para contribuir para a reflexão sobre a questão escolar hoje, também no Brasil.

As reflexões deste texto tomam por base a publicação, na Alemanha, do livro L ob der D isziplin - E ine Streitschrift, E logio à disciplina - uma polêmica e os contrapontos levantados por diversos pesquisadores, pedagogos e educadores, daquele país divulgados na obraV om M issbrauch der D isziplin. A ntworten der W issenschaft auf B ernhard Bueb, Sobre o uso abusivo da disciplina. Respostas da ciência a Bernhard Bueb.

Antes de abordar a temática da disciplina, apresento um breve retrospecto histórico e cultural sobre os sentidos e significados de tornar-se humano e, nessa perspectiva, o tornar-se cidadão se sobressai como possibilidade de repensar a construção humana.

Rev. Diálogo Educ., Curitiba, v. 9, n. 28, p. 557-569, set./ dez. 2009 


\section{Tornar-se humano, tornar-se cidadão: uma análise histórico-cultural}

O s humanos constituem-se como uma única espécie no planeta inteiro. A pesar de sua imensa diversidade, dos diferentes tons de pele, diferentes cores de cabelo, das diferentes formas, diferentes biotipos, nos tornamos hegemônicos no planeta inteiro. Nossa espécie homo sapiens sobreviveu graças a sua enorme capacidade de se adaptar a diferentes ambientes, inclusive determinando seus próprios corpos, sua própria cor de pele, para se adaptar as diferentes regiões, diferentes climas com suas correspondentes variações de temperatura e incidência de luz solar.

A história da formação da humanidade é muito rica para nos ajudar na compreensão de um princípio que podemos imputar como ético: - todos nós seres humanos somos iguais na diversidade. Não há raças humanas, há uma espécie humana, que habita o planeta inteiro. A ciểncia tem nos ajudado a compreenderisso. Nossas diferenças genéticas são muito pequenas. Um sueco, branco, que vive num país que tem oito meses de sombra durante 0 ano, com um longo inverno, é tão próximo de um africano, negro, que vive na Somália, que a diferença pode ser de meio por cento, quando falamos de D NA. A diferença genética, ou seja, as cadeias de cromossomos que definem nossas diferenças aparentes nos aproximam uns aos outros nesta imensa humano/ irmandade que habita o planeta inteiro e que se produziu a si mesmo pela capacidade de produzir conhecimento. Essa é uma lição importante!

O s gregos, há2.500 anos, deram uma dimensão novaà concepção sobre a condição humana. Partindo da pergunta ontológica: - qual é a razão e o sentido da existência humana?, ou seja, - por que nós, seres humanos, existimos?, constroem uma resposta historicamente original, que nenhum outro povo com sua cultura anterior ou contemporânea aos gregos igualou.

O smesopotâmios, os egípcios, as culturas orientais, invariavelmente respondem esta pergunta deforma mítica. Paraestas culturas foram os deuses que inventaram os humanos, e querem que eles vivam assim e se organizem dessa forma, honrando seus criadores. Ass respostas são míticas, como por exemplo: - "no começo dos tempos o sol e a lua se casaram e do seu amor surgiram os humanos como filhos desses deuses originais". O s gregos fazem a pergunta "- qual o sentido ou significado da existência humana?", mas dãose conta de que se nós seres humanos somos capazes de fazer esta pergunta, a fazemos com o uso da ferramenta humana da razão, sendo assim, uma respostaválida para uma pergunta racional devenecessariamente tera mesma qualidade da pergunta e do perguntador, ser racional.

Rev. Diálogo Educ., Curitiba, v. 9, n. 28, p. 557-569, set./ dez. 2009 
A resposta dos gregos para o sentido e o significado da existência humana é a de que nós seres humanos existimos para nos tornarmos plenos, completos, bons e belos, enfim dignos do uso das prerrogativas do cidadão da pólis. Ser pleno, completo, cidadão é ser feliz! Para os gregos um ser humano não nasce humano, torna-se humano por viver entre humanos. Eles percebem logo que os seres humanos constituemse seres humanos porque produzem uma natureza que resulta da ação de suas vontades e que vem em proveito deles mesmos, a cultura.

A educação está fundamentalmente ligadaà ideia de cidadania. Não se pode ser cidadão numa cidade que não garante educação de qualidade para todos, sejam eles crianças, jovens, adultos ou idosos. Não há uma educação em que frequentando a escola eu me torne apenas capaz de reproduzir as informações quealguns querem que sejam veiculadas e reproduzidas. Porque isso não é, para os gregos, educação. Educação que reproduz informação, que reduz nossas práticas escolaresameratransmissão daquilo quenós chamamos de matérias, dos conteúdos próprios das disciplinas, isso não é educação. Isso é mera informação, reprodução de informação.

Para os gregos isso não é educação, isso é escolaridade. Isso não liberta ninguém e em não libertando ninguém, não garante a sua condição de cidadão. Porque construção de cidadania não é projeto que se atribui ao outro. Cidadania é construção individual e coletiva no espaço social da cultura humana. E uma escola que se fundamenta na mera transmissão de informação na garantia de sua reprodução, é conservadora por princípio negando a possibilidade que os gregos definiram, na origem de nossa civilização ocidental, como destino da existência humana: plenitude e completude, como condição de possibilidade da felicidade humana.

Para os gregos, educação de verdade é aquela que não dispensa a informação, mas que não a transforma em objetivo das práticas escolares. A informação é a matéria prima com a qual nós, educadores, trabalhamos. Educação de qualidade para os gregos, garantia de cidadania e, portanto, de realização do humano, é aquela em que o filósofo/ educador, por interessar-se pelo humano e prezar o conhecimento, é destinado socialmente, por sua livre vontade e por decisão coletiva, a realizar-se no espaço de construção de cidadania que é o da educação.

O filósofo/ educador, usando da informação, cria espaços de qualificação para a problematização. Ou seja, quem passa por esses espaços de problematização, deveria tornar-se capaz de, em recebendo a informação, problematiza-la. E neste processo, tornar-se capaz de compreender o passado, entender 0 presente, projetar e construir 0

Rev. Diálogo Educ., Curitiba, v. 9, n. 28, p. 557-569, set./ dez. 2009 
futuro. Então, viver a experiência da escola qualifica para 0 agir politicamente, ou seja, para agir na pólis, contribuindo para a sua qualificação e evolução política.

Esta introdução, ainda que primária, busca orientar a reflexão para a discussão contemporânea sobre a educação, a escola e os educadores, quanto aos usos e abusos da disciplina, que é o que segue.

\section{E logio à disciplina: entre oleiros e jardineiros}

Bernhard Bueb, ${ }^{1}$ diretor entre os anos de 1974 e 2005 do Internato Internacional Schloss Salem, na Baviera, Alemanha, lançou em 2006 um livro que rapidamente alcançou nove edições. Um sucesso editorial e um terremoto entre pais e pedagogos. O livro L ob der D isziplin - E ine Streitschrift, E logio à disciplina - uma polêmica, parte da constatação de que não há mais consenso sobre como devem ser educadas as crianças e os jovens. Nas famílias e nas escolas a insegurança sobre os procedimentos adequados tem dado o tom das práticas pedagógicas. Pais e professores têm escrúpulos em estabelecer regras claras e mostrar limitese, segundo Bueb, porisso mesmo são transformados em fantoches da indisciplina e crescente violência escolar.2

Partindo da tese de que as crianças e os jovens não são mais educados nas suas famílias e nem nas escolas que frequentam, mas simplesmente crescem nelas, isto é, se tornam adultos da espécie humana, mas não são humanizados, Bueb afirma que estão todos submetidos a um ambienteagressivo em todas as suasdimensões:- pelosmeiosdecomunicação que divulgam uma cultura de consumo e de concorrência e pela falta de perspectivas em relação a um futuro incerto. Os adultos individualmente e a sociedade não oferecem esperança quanto ao que virá às crianças e aos jovens e agravam o quadro roubando-lhes valores morais e religiosos, segundo Bueb, necessários para alicerçarem ideais e projetos de vida.

É interessante a reprodução no fundamento das teses de Bueb, da ideia de uma crise da escola, formulada pelo internacionalmente

1 Bernhard Bueb nasceu em 1938, estudou filosofia e teologia. Depois de doutorar-se, trabalhou como assistente do professor Hartmut von Hentig, na Universidade de Bielefeld, Alemanha. De 1974 a 2005 dirigiu a Internatsschule Schloss Salem, Baviera, Alemanha.

2 Quem lê o livro de Bernhard Bueb não pode deixar de compará-lo com o livro de Içami Tiba, D isciplina: limite na medida certa. Novos paradigmas, e entender por que certos manuais para pais e professores se transformam em bestseller. Em 2006 o livro alcançou no Brasil sua 77ạ edição.

Rev. Diálogo Educ., Curitiba, v. 9, n. 28, p. 557-569, set./ dez. 2009 
renomado professor emérito Hartmut von Hentig, com o qual o autor de E logio à disciplina, trabalhou como assistente na Universidade de Bielefeld, Alemanha, especialmente na direção da escola experimental fundada naquela universidade em 1974.

Para Hentig, as escolas não alcançam seus objetivos, as escolas não alcançam seus alunos. D iante desta crise são possíveis duas respostas imediatas: - a sociedade desonera a escola de tudo e de todas as atribuições que não dizem respeito diretamente ao seu papel original, de forma a conseguir aumentar sua produtividade formativa; ou, - a escola transforma-se num ambiente de vida e de experiência pessoal e social onde a pedagogia possa ser possível. As duas alternativas podem conduzir a erros se não formularmos com precisão o que é e 0 que pretende o processo formativo que localizamos e realizamos, preferencialmente, na instituição escolar. Na primeira, a escola corre 0 risco de tornar-se uma instituição para adaptação de alunos ao desenvolvimento da sociedade. Na outra, a escola corre o risco de confundir sua finalidade com pedagogia social. D esses modelos de escola não surgirá um ser humano capaz de compreender o mundo e contribuir para sua transformação (HENTIG , 2007). Esta constatação parece indicar para os dois autores os rumos a serem tomados: - uma formal recuperação dos princípios da autoridade dos professores e da escola através do uso de uma disciplina igualmente formal.

Esse último aspecto ressalta uma característica marcante de todo o trabalho de Hentig, reproduzido na obra da Bueb. Ao contrário do movimento de 1968 fundamentado na crítica a todo o sistema ocidental, Hentig defende uma escola onde a educação contribua para esclarecer e problematizar o sentido do papel ordenador (também coercitivo) das instituições criadas pelos homens, de forma a alcançar sua adesão à ordem institucional, necessária ao desenvolvimento das sociedades.

0 autor de E logio à disciplina, falando da escola, diz que a experiência autoritária do nacional-socialismo na Alemanha, entre 1933 e 1945, levou a situação atual de absoluta crise de autoridade naquele país e de sorte em todo o mundo ocidental. A centralização autoritária de poder ilimitado nas mãos de Hitler, o desmantelamento e proibição de quaisquer organizações de participação civil, a revogação dos direitos fundamentais, a extinção da liberdade de opinião e de imprensa e, finalmente, a organização, regulação e controle absoluto de todo o sistema escolar alemão em todos os seus níveis, criaram as bases para uma pedagogia liberal. Pedagogia não diretiva que desembocou em uma prática escolar incapaz de conter a violência e resolver conflitos em sala de aula.

Rev. Diálogo Educ., Curitiba, v. 9, n. 28, p. 557-569, set./ dez. 2009 
Considerando as colocações de Bueb, muitos professores e pedagogos brasileiros, desesperados com 0 crescimento da violência e incapazes, igualmente, de solucionar conflitos nas salas de aula de nossas escolas, poderão considerar nossos problemas no Brasil, de certo modo e mantidas as devidas proporções, semelhantes aos vividos hojenaAlemanha.

No Brasil, nossa mais recente experiência autoritária, no período entre 1964 e 1985, com cerceamento de liberdades individuais e direitos fundamentais, semelhante ao ocorrido na Alemanha nazista, seria a explicação, na opinião dos mais apressados, para a excessiva liberdade ou liberalismo em nossas escolas e nas práticas escolares de nossos professores. Enfim, o autoritarismo do período militar justificaria os excessos de liberdade nos tempos presentes, também na escola.

Para Bueb há dois modelos de professor para a proposta que defende: - a de retomar o controle sobre a educação das crianças e dos jovens com disciplina. 0 oleiro ( $\mathrm{T}$ öpfer) que molda a argila macia para darlhe a forma desejada, e o jardineiro ( $\mathrm{G}$ ärtner) que cultiva, nutre a planta fertilizando-lhe o terreno e controlando-lhe as pragas.

0 professor que adota a prática do oleiro como o fundamento de suas práticas escolares deseja formar as crianças e osjovens colocados sob a sua tutela. Ele interfere, limita, estimula, disciplina, cria ambientes para exercício de liberdade crescente de seus alunos e os conduz para a liberdade responsável da vida adulta (BUEB, 2006, p. 15-16).

A prática do jardineiro como inspiração para a prática docente impõe menos autoridade e menos condução. Esse professor ocupa-se em criar condições adequadas no ambiente escolar para o crescimento integral dos alunos sob a sua guarda. Menos intervenção e mais confiança na autodisciplinae na autocompreensão das responsabilidades da liberdade conquistada com o crescimento para a vida adulta (BUEB, 2006).

Nas palavras de Bueb (2006, p. 16):

O oleiro e o jardineiro representam dois estilos legítimos de educar, que raramente aparecem em sua forma pura. Geralmente encontramos uma mistura tendência maior ou menor a um destes pólos. Os dois estilos trazem perigos em si, o estilo do oleiro poder desenvolver-se em autoritarismo e 0 estilo do jardineiro em não-educação. ${ }^{3}$

3 Der Töpfer und der Gärtner repräsentieren zwei legitime Stile der Erziehung, die in Reinform selten vorkommen, moistens treffen wir eine Mischung mit einer Neigung zum einen oder anderen Pol an. Beide Stile Bergen Gefahren in sich, der Stil des Töpfers kann in autoritäre Erziehung ausarten und der Stil des Gärtners in Nicht-Erziehung.

Rev. Diálogo Educ., Curitiba, v. 9, n. 28, p. 557-569, set./ dez. 2009 
Segundo o autor, os alemães, depois de uma experiência de tradição educativa autoritária que desembocou na ditadura nazista, quiseram tornar-se uma nação de jardineiros, mas acabaram transformando-se numa nação de não-educadores. Esqueceram que jardineiros também intervêm, podam e orientam o crescimento de suas plantas e evitam falhas e defeitos em seu desenvolvimento, como deveriam fazer professores com seus alunos.

Para Bueb, educar significa sempre orientar, a própria palavra pedagogo indica com precisão isso, em sua origem na língua grega: - condutor de crianças. Q uem conduz espera ser seguido. Como crianças não nascem obedientes, elas ignoram orientações, revoltamse contra medidas educativas, não atendem pedidos e usam de todos os meios para exercer suas vontades. Conter acessos de raiva de uma criança cujos motivos nem sempre são inteligíveis sem perder 0 controle, sem usar de violência ou castigos exige, naturalmente, de pais e professores elevada autodisciplina. Esta autodisciplina corresponde, segundo Bueb (2006, p. 17) ao grau de instrução e cultura de pais e professores. Educação e formação não se realizam sem conflitos. Encarar os conflitos, não retroceder no exercício e no reconhecimento do papel responsável de educador nos espaços privados (família e grupos de amigos) e públicos (supermercados, restaurantes ou na rua) exige coragem de agir consequentemente mesmo sob o olhar de expectadores.

Bueb ressalta que coragem de educar é, sobretudo, coragem para o exercício da disciplina. Afirma que a disciplina, que é a filha rejeitada da moderna pedagogia, precisa ser reconhecida como fundamento de todo e qualquer ato educativo. Ainda que disciplina represente tudo o que naturalmente desprezamos: orientação, determinação, obediência, reconhecimento de autoridade e hierarquia, contenção e submissão da própria vontade.

Toda restrição ao exercício da vontade própria é permitida desde que contribua para alcançar um objetivo claramente definido e reconhecido socialmente como necessário e parte do processo educativo. Disciplina é ato formativo que sempre inicia com estranhamento, por apresentar-se como determinação externa ao sujeito - heteronomia -, mas que deve terminar naturalizado, como habitus incorporado a existência da persona, - autonomia. D a disciplina deve decorrer, quando se trata de educação, a autodisciplina, objetivo que não pode ser alcançado sem amor responsável de pais e educadores para com as crianças e os jovens.

Rev. Diálogo Educ., Curitiba, v. 9, n. 28, p. 557-569, set./ dez. 2009 


\section{Sobre o uso abusivo da disciplina}

Como uma reação ao livro e às ideias de Bernhard Bueb, mas também como testemunho de seu extraordinário sucesso, foi lançado, no início do ano de 2007, V om M issbrauch der D isziplin. A ntworten der W issenschaft auf B ernhard Bueb, Sobre 0 uso abusivo da disciplina. Respostas da ciência a B ernhard Bueb (BRUMLIK, 2007). A obra organizada por Micha Brumlik, professor de teoria da formação e da educação na Universidade Johann Wolfgang $\mathrm{G}$ oethe, em Frankfurt no Meno, Alemanha, e diretor do Instituto Fritz Bauer - Centro de Estudos e D ocumentação sobre a História e as consequências do Holocausto, conta com a colaboração de oito renomados professores, cientistas e escritores da área de educação. ${ }^{4}$

0 professor emérito de pedagogia social da Universidade de Tübingen, Hans Thiersch, examina as necessidades e desejos dos educadores profissionais e privados em tempos de grandes transformações sociais. Conclui que o tratado de Bueb não dá conta satisfatoriamente da profunda crise por que passa a educação na Alemanha e no ocidente. Escola e educadores passam por uma grave crise de autoridade cujas causas estão na perda de valores e princípios e na fragilidade das novas propostas. Há nessa terra arrasada espaço para boa lavratura e promissores experimentos, desde que não se reduzam a banal alternativa, como a de Bueb, de buscar um futuro nos rotos fragmentos do passado (BRUMLIK, 2007, p. 12-32).

Que tanto o estilo de Bueb quanto suas teses não são novas, nem tampouco originais, é o que mostra a professora de teoria geral da educação na Universidade de Bielefeld, Sabine Andresen. Em lúcida e historicamente fundamentada análise indica a relação entre as ideias do autor de E logio à disciplina e um movimento de mais de 100 anos de pedagogos masculinos como reação a uma pedagogia centrada na criança. Mostra-se aí que Bueb consciente ou inconscientemente perfilase a uma tradição masculizada e misó gina que, desde o começo da idade moderna, busca preservarvalores como a virilidade, disciplina, obediência e ordem ligadas a uma concepção militarizada de educação e de formação. Este movimento pedagógico configurou-se a partir da reação diante de uma crescente humanização do campo educativo e escolar associado à feminização do magistério (BRUMLIK, 2007, p. 76-99).

Karin Amos, professora e pesquisadora em teoria comparada da educação, na Universidade de Tübingen, examina as práticas e os

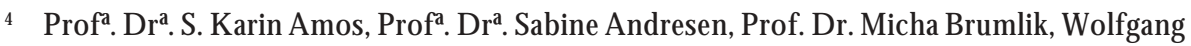
Bergmann, D r. Claus Koch, Prof. D r. Frank-Olaf Radtke, Prof. D r. D r. Manfred Spitzer, e Prof. Dr. Dr. hc. Hans Thiersch.

Rev. Diálogo Educ., Curitiba, v. 9, n. 28, p. 557-569, set./ dez. 2009 
fundamentos da formação de elites em internatos, buscando desconstruir os argumentos de Bueb e mostrando o quanto suas teses, ancoradas na experiência de ex-diretor de um dos mais importantes e mais caros internatos da E uropa, contribuem para reforçar princípios pedagógicos antidemocráticos e totalitários (BRUMLIK, 2007, p. 134-168).

0 reconhecido terapeuta de crianças e jovens Wolfgang Bergmann, no capítulo A utoritär und ahnungslos, weltfremd und anti-modern oder: W ie man pädagogische B estseller schreibt, autoritário e desorientado, alienado e anti-moderno - ou: como se escreve um bestseller pedagógico (BRUMLIK, 2007, p. 33-51), do livro organizado pelo professor Brumlik, mostra o quanto à crítica de Bueb ao que ele chama de excessiva psicologização da educação, transforma-se em traição da promessa de contribuir, através da utilização de uma disciplina formal, para conduzir crianças e jovens por um caminho que os conduza seguros e felizes através do futuro. Por certo é preciso reconhecer que tratados pedagógicos como o livro de Bueb têm pressupostos e consequências políticas de grande repercussão. Com isso ainda não se discutiu a qualidade destas consequências políticas.

O psicólogo Claus Koch (BRUMLIK, 2007, p. 100-133) questiona a consistência das críticas de Bueb aos princípios educativos da geração libertária dos anos 1968. A contribuição de Koch choca ao mostrar, em exemplos e detalhes, como a representação de Bueb sobre as crianças e os jovens aproxima-se das teorias e práticas pedagógicas indicadas pelos nacional-socialistas.

0 conhecido pesquisador do cérebro humano Manfred Spitzer lembra que os resultados da educação escolar estão, ao contrário do que Bueb ignora, também vinculados as disposições físicas eao desenvolvimento neuropsicológico de crianças e jovens. Estes por sua vez, determinados pelas condições e contextos sociais e materiais de existência, definem com muito mais profundidade a qualidade do desenvolvimento da aprendizagem eaformação do sujeito. Ajudam a compreender com maior clareza as razões da indisciplina e as causas da violência entre crianças e jovens nas escolas e fora delas (BRUMLIK, 2007, p. 169-203).

Frank-O laf Radtke, leciona em Frankfurt no Meno Teoria G eral da Educação e pesquisa pedagogia intercultural entre imigrantes, referese ao livro E logio à disciplina questionando sobre o fundamento de uma pedagogia moderna comprometida com a concepção iluminista de Imannuel Kant, estabelecendo uma relação instigante sobre as teses de Bueb e os seus preceitos. O autor do último capítulo do livro organizado por Brumlik (W iederausfrüstung im L ager der E rwachsenen: Bernhard Buebs Schwarze Pädagogik für das 21. Jahrhundert, Prontidão no campo dos adultos: a peda gogia conservadora/ reacionária deB ernhard Bueb para o século 21, (BRUMLIK, 2007, p. 204-242) pergunta-se se 0 autoritarismo não estaria mesmo na

Rev. Diálogo Educ., Curitiba, v. 9, n. 28, p. 557-569, set./ dez. 2009 
base teórica da pedagogia e educação modernas. Se tal reflexão for feita é provável, segundo Radtke, que a tradição pedagógica do ocidente, assim como Bueb acaba demonstrando, contribui para uma legitimação de um domínio tecnocrático e a reprodução de uma cultura de consumo.

O livro organizado pelo professor Brumlik (2007) apresenta-se como contraponto ao de Bueb e quer questionar mesmo aqueles que receberam com simpatia o E logio à disciplina (2006), sobre as consequências das ideias de seu autor. A crença nos resultados de uma prática escolar e de uma educação alicerçada nos princípios de um relacionamento libertador e humano com nossas crianças e jovens (BERGMANN, 2006, p. 76-81). A prática de uma educação para a autonomia, levada a efeito por pais e educadores durante anos e mesmo décadas, não pode esmorecer diante de uma nova onda neoconservadora. Afinal, o que distingue pedagogia disciplinar de quartel da boa autoridade? A utoridade que fundamenta 0 trabalho sincero e duro de educadores que buscam realizar os objetivos de uma educação para a liberdade e para o bem.

\section{CONSIDERAÇÕES FINAIS}

Neste espaço para as considerações finais cabe ressaltar que a crise da instituição escola não se constitui num elemento novo para o campo educacional. Esta crise de valores morais e éticos vem ao longo das épocas se delineando devido aum grandenúmero defatores sócio-político, econômicos e culturais. Compreender as formas como esta crise se apresenta no âmbito escolar é um grande desafio a ser enfrentado pelos professores. Enfrentar a violência que invade a escola e a que nela se esconde, que nela é produto e também é produtor, é fundamental para um agir educativo.

Questionar aquilo que está dado, indagar-se sobre o não alcance de objetivos propostos pela escola, discutir a formação humana atual, bem como os valores e normas estabelecidas (ou a falta deles) é imprescindível para repensarmos nossa prática docente e, sobretudo, a convivência escolar.

Mais do que oleiros e jardineiros, os professores são protagonistas num processo de construção da humanidade, sua tarefa envolve o educar e o conviver. Um educar e um conviver que dizem respeito a toda uma proposta de convivência interpessoal, baseada não no controle, na obediência, nem na submissão, mas na autonomia, na compreensão e no respeito.

Às vezes, falamos como se não houvesse alternativa para um mundo de luta e competição, e como se devêssemos preparar nossas crianças e jovens para essa realidade. Tal atitude de baseia num erro e

Rev. Diálogo Educ., Curitiba, v. 9, n. 28, p. 557-569, set./ dez. 2009 
gera um engano. Não é a agressão à emoção fundamental que define 0 humano, mas o amor, a coexistência, a aceitação do outro como legítimo outro na convivência (MATURANA, 2000). Não é a luta o modo fundamental de relação humana, mas a colaboração.

É necessária uma postura reflexiva no mundo em vivemos, são necessários a aceitação e o respeito por si mesmo e pelos outros sem a premência da competição. A prende-se a conhecer e a respeitar o mundo no espaço em que se age e conhece. Aprende-se a refletir na aceitação e respeito por mim mesmo, o que para Maturana (2000) é fundamental para que possamos aceitar o outro. A partir da aceitação de mim mesmo é que poderei aceitar o outro como legitimo na sua diferença, essa atitude permitirá aprender qualquer "que fazer". A ceitar-se e aceitar 0 outro são atitudes fundamentais para a construção de uma educação, baseada no respeito e na superação da violência.

\section{REFERÊNCIAS}

BERG MANN, W. Gute Autonität: grundsätze einer zeitgemässen erziehung. München und Wien: Beltz, 2006.

BRUMLIK, M. (Hrsg.). Vom missbrauch der disziplin: antworten der wissenschaft auf bernhard bueb. Weinheim und Basel: Beltz, 2007.

BUEB, B. Lob der disziplin: eine streitschrift. Berlin: List, 2006.

HENTIG, H. von. Die schule neu denken: eine übung in pädagogischer vernunft. München und Wien: Beltz, 2003.

Bildung: eins essay. München unda Wien: Beltz, 2007.

MATURANA, H. Formação humana e capacitação. Petrópolis: Vozes, 2000.

Recebido: 14/ 03/ 2009

Received: 03/ 14/ 2009

Aprovado: 02/ 04/ 2009

A pproved: 04/ 02/ 2009

Revisado: 17/ 09/ 2009

Reviewed: 09/ 17/ 2009

Rev. Diálogo Educ., Curitiba, v. 9, n. 28, p. 557-569, set./ dez. 2009 